\title{
ASPECTOS BIOLÓGICOS E PARASITISMO DE Hymenochaonia delicata Cresson (HYMENOPTERA: BRACONIDAE) SOBRE Gymnandrosoma aurantianum LIMA (LEPIDOPTERA: TORTRICIDAE) EM LABORATÓRIO.
}

\author{
Patrícia Milano ${ }^{\text {, Evoneo Berti Filho }}{ }^{1}$, José Roberto Postali Parra ${ }^{1}$, Sheila. Salles de Carvalho ${ }^{1}$ \\ 'Departamento de Entomologia, Fitopatologia e Zoologia Agrícola, ESALQ/USP,Piracicaba, CEP 13418-900,E- \\ mail: patmilano@gmail.com, eberti@esalq.usp.br,jrpparra@esalq.usp.br, sscarval@esalq.usp.br
}

\section{RESUMO}

Hymenochaonia delicata Cresson (Hymenoptera: Braconidae), um parasitóide larval do bicho-furão-dos-citros Gymnandrosoma aurantianum (Lepidoptera: Tortricidae), foi recentemente registrado no Brasil. Aqui, descrevem-se os esforços iniciais para o desenvolvimento de uma técnica de criação para produzir em grande número deste inseto para programas de controle biológico aumentativo ou inundativo. Também se fornece um número de informações detalhadas sobre muitos aspectos da biologia básica deste inimigo natural. $\mathrm{O}$ período ovo-adulto de machos e fêmeas de $H$. delicata foi de 30,7 dias. A viabilidade pupal para ambos os sexos foi de $76 \%$ e as fêmeas viveram 14 dias. $H$. delicata preferiu parasitar as larvas de $3^{\underline{0}}$ ínstar de $G$. aurantianum, embora os $1^{\underline{0}}, 2^{\underline{0}}$ e $4^{\underline{0}}$ ínstares também tenham sido parasitados. No entanto, a porcentagem de parasitismo obtida em condições de laboratório por três gerações consecutivas foi muito baixa $(8,5,2,6$, e $3,0 \%$ para as gerações $F 1, F 2$ e F3, respectivamente), não havendo parasitismo na $4^{\mathrm{a}}$ geração. O parasitismo ocorreu somente quando o hospedeiro se encontrou dentro do fruto (laranja cv. 'Pêra'), indicando que as interações hospedeiro-fruta hospedeira são importantes para o processo de seleção hospedeira por este inimigo natural, devendo ser investigadas futuramente. A adição de óleo cítrico na dieta artificial do hospedeiro larval aumentou a atração da fêmea do parasitóide até seu hospedeiro quando oferecido fora da fruta hospedeira. Entretanto, nenhum parasitismo foi observado.

Palavras-chave: Bicho-furão-dos-citros, Controle biológico, Macrocentrinae

\section{BIOLOGICAL ASPECTS AND PARASITISM OF Hymenochaonia delicata CRESSON (HYMENOPTERA: BRACONIDAE) ON Gymnandrosoma aurantianum LIMA (LEPIDOPTERA: TORTRICIDAE) IN LABORATORY.}

\begin{abstract}
Hymenochaonia delicata Cresson (Hymenoptera: Braconidae), a larval parasitoid of the citrus fruit borer, Gymnandrosoma aurantianum (Lepidoptera: Tortricidae), was recently recorded in Brazil. We describe our initial efforts for developing a rearing technique to aid on the production of large numbers of this parasitoid for augmentative or inundative biocontrol programs. We also provide a number of detailed information on many aspects of the basic biology of this natural enemy. Males and females egg to adult developmental time of $H$. delicata was about 30.7 days. Pupal viability for both sexes was $76 \%$ and females lived 14 days. $H$. delicata prefered to parasitize $G$. aurantianum $3^{\text {rd }}$ instar larvae although $1^{\text {st }}, 2^{\text {nd }}$ and $4^{\text {th }}$ instars larvae were parasitized. However, the percentage obtained in laboratory conditions for three consecutive generations was very low $(8.5,2.6$ and $3.0 \%$ for $F 1, F 2$ and F3 generations,
\end{abstract}


respectively), with no parasitization at all at the $4^{\text {th }}$ generation. Parasitization only occurred when hosts were inside the host fruit (orange fruits cv. 'Pera'), indicative that the host -host fruit interactions are important in the host selection process by this natural enemy, and should be further investigated. The addition of citric oil to the host larval artificial diet increased host larvae attractiveness to parasitoid female when host was offered out of the host fruit. Nevertheless, no parasitization was observed.

Key words: Citrus fruit borer, Biological control, Macrocentrinae

\section{INTRODUÇÃO}

Hymenochaonia delicata é um braconídeo pertencente à subfamília Macrocentrinae (Figura 1), que contém somente quatro gêneros no Novo Mundo: Macrocentrus, Hymenochaonia, Austrozele e Dolichozele. Os dois primeiros gêneros possuem longo ovipositor, atacando seus hospedeiros quando escondidos em galerias, folhas enroladas ou frutos, ao contrário de Austrozele e Dolichozele que atacam hospedeiros mais expostos como lepidópteros pertencentes às famílias Arctiidae e Geometridae (Wharton et al.,1997). O gênero Hymenochaonia é endêmico do Novo Mundo e embora tenha sido introduzido na Itália, não há registro sobre sua ocorrência ou adaptação naquele país (Achterberg, 1993). Pouco se sabe sobre $H$. delicata a não ser que parasita lagartas de $3^{\circ}$ ínstar de lepidópteros das famílias Tortricidae, Pyralidae e Noctuidae (Wharton et al., 1997).

No Brasil, $H$. delicata foi encontrado no Estado de São Paulo em pomares de laranja Pêra, atacando Gymnandrosoma aurantianum, o bichofurão-dos-citros. Garcia (1998) relatou que, dos parasitóides emergidos em laboratório, de lagartas coletadas no campo, o mais freqüente foi $H$. delicata. $\mathrm{O}$ autor observou que as lagartas de $G$. aurantianum, em alguns lotes de laranja, foram parasitadas em até $56,4 \%$, sugerindo a necessidade de estudos em relação ao potencial deste inimigo natural para futuros programas de controle biológico. Assim, foram coletados 2300 frutos de laranja Pêra infestados por G. aurantianum na Fazenda Sete Lagoas em Mogi-Guaçu, SP. Em laboratório, os frutos foram abertos e as lagartas de $G$. aurantianum retiradas e transferidas para tubos de vidro de $8 \mathrm{~cm}$ de altura e $2 \mathrm{~cm}$ de diâmetro contendo dieta artificial (Garcia \& Parra, 1999) para a obtenção de $H$. delicata. Foram obtidos apenas trinta adultos do parasitóide sendo dezessete fêmeas e treze machos.

Visando estabelecer uma criação estoque de $H$. delicata alguns frutos de laranja pêra foram infestados em laboratório. Lagartas de $1^{\circ}, 2^{\circ}, 3^{\circ}$ e $4^{\circ}$ ínstares de $G$. aurantianum foram colocadas em diferentes frutos em número de dez para cada ínstar. Cada fruto foi colocado em uma gaiola formada por copo plástico transparente de $700 \mathrm{ml}$ (Fig. 2A), o qual foi tampado com uma tampa plástica $\mathrm{e}$ a infestação permitida por $24 \mathrm{~h}$. Após este período, os frutos foram retirados dos copos e transferidos para uma gaiola de madeira de $1 \mathrm{~m} \times 40 \mathrm{~cm} \times 60 \mathrm{~cm}$ (Fig. 2B). Os trinta adultos obtidos, a partir dos frutos coletados em campo, foram liberados nesta gaiola e cada fruto infestado em laboratório permaneceu durante $48 \mathrm{~h}$ em exposição aos parasitóides sendo, em seguida, retirados e transferidos para outra gaiola de madeira. 


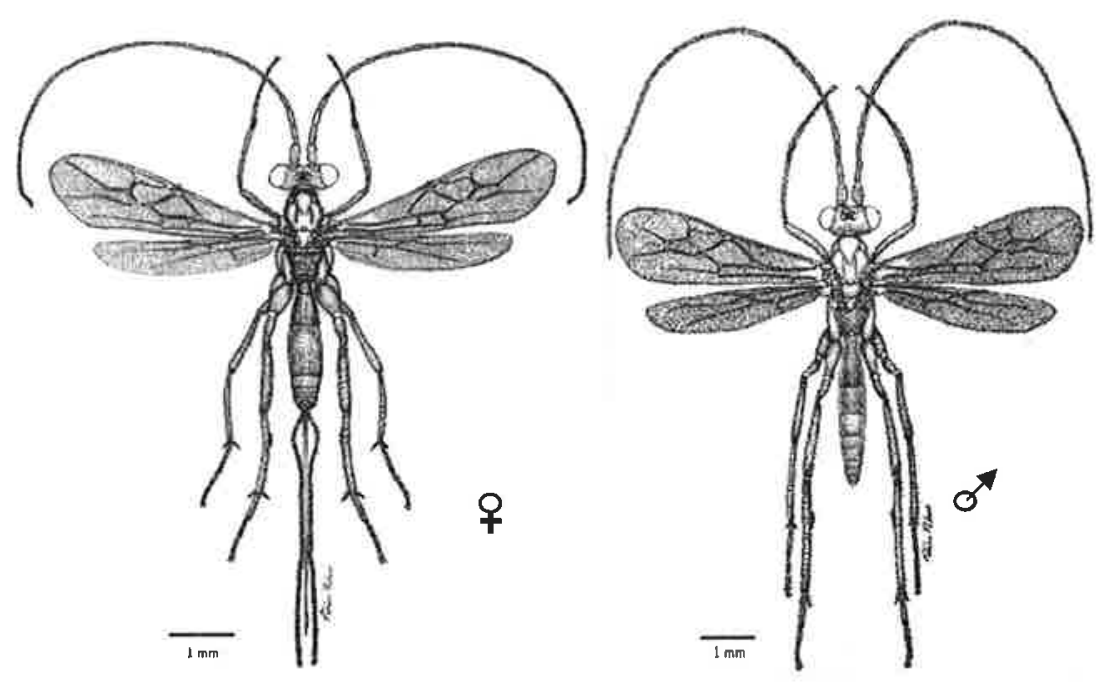

Figura 1. Adultos de Hymenochaonia delicata

Diferentes quantidades de lagartas de cada ínstar de $G$. aurantianum foram expostas ao parasitismo (Tabela 1).

Como alimentação aos adultos de $H$. delicata forneceram-se misturas de mel, pólen comercial e água (1:1:1); mel, levedura e água $(1: 1: 1)$; mel, pólen comercial, levedura e água $(1: 1: 1: 1)$; pólen comercial; levedura e mel puro, buscandose uma fonte de alimento adequada aos parasitóides. No entanto, os adultos alimentaram-se apenas de mel puro, porém, não se pode afirmar que esta fonte de alimento seja a mais adequada, uma vez que os adultos movimentaram-se muito em busca de alimento sugerindo que em condições de campo, néctar e pólen presentes em grandes quantidades possam suprir melhor as necessidades destes insetos.
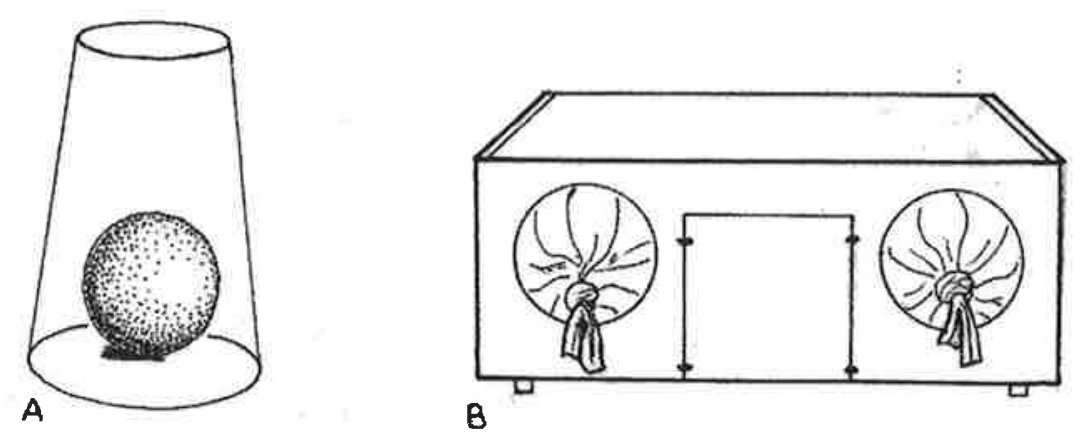

Figura 2. A-Gaiolas (copo plástico transparente de $700 \mathrm{ml}$ ) para a infestação de frutos de laranja Pêra por G. aurantianum; B- Gaiola de madeira utilizada para manutenção de $H$. delicata. 
Tabela 1. Porcentagem de parasitismo de Hymenochaonia delicata sobre lagartas 1 a $4^{\circ}$ ínstar de Gymnandrosoma aurantianum em três gerações de laboratório.

\begin{tabular}{ccccccc}
\hline \multirow{2}{*}{ Instar } & \multicolumn{2}{c}{$\mathbf{1}^{\mathbf{a}}$ Geração } & \multicolumn{2}{c}{$\mathbf{2}^{\mathbf{a}}$ Geração } & \multicolumn{2}{c}{$\mathbf{3}^{\mathbf{a}}$ Geração } \\
& oferecidas & $\begin{array}{c}\text { parasitismo/ } \\
\mathrm{n}^{\mathbf{o}} \text { de lag. }\end{array}$ & $\begin{array}{c}\text { Frutos/lag. } \\
\text { oferecidas }\end{array}$ & $\begin{array}{c}\text { parasitismo/ } \\
\mathrm{n}^{\mathbf{o}} \text { de lag. }\end{array}$ & $\begin{array}{c}\text { Frutos/lag. } \\
\text { oferecidas }\end{array}$ & $\begin{array}{c}\text { parasitismo/ } \\
\mathrm{n}^{\mathbf{0}} \text { de lag. }\end{array}$ \\
\hline $\mathbf{1}^{\mathbf{o}}$ & $16 / 160$ & $3,75 \% / 6$ & - & - & - & - \\
$\mathbf{2}^{\mathbf{0}}$ & $35 / 350$ & $9,14 \% / 32$ & $12 / 120$ & $1,66 \% / 2$ & $11 / 110$ & 0 \\
$\mathbf{3}^{\mathbf{o}}$ & $40 / 400$ & $8,50 \% / 34$ & $45 / 450$ & $3,77 \% / 17$ & $53 / 530$ & $3,77 \% / 20$ \\
$\mathbf{4}^{\mathbf{o}}$ & $2 / 20$ & $35 \% / 7$ & $27 / 270$ & $3,40 \% / 3$ & - & - \\
\hline
\end{tabular}

A partir das primeiras lagartas oferecidas ao parasitóide obtiveram-se sessenta e oito adultos de $H$. delicata dos quais, quarenta e nove machos e dezenove fềmeas (Tabela 2). Apesar do grande número de machos, foi possível obter mais duas gerações do parasitóide em laboratório. No entanto, o número de lagartas parasitadas foi diminuindo ao longo das gerações (Tabela 1) não sendo possível obter uma $4^{\text {a }}$ geração deste inseto.

Observou-se uma preferência de $H$. delicata por lagartas de $3^{\circ}$ ínstar embora lagartas de $1^{\circ}, 2^{\circ}$ e $4^{\circ}$ ínstares também possam ser parasitadas (Tabela 1). A dificuldade de se encontrar novos adultos em campo colaborou para a queda da população. Embora o método de criação de $H$. delicata tenha proporcionado três gerações do parasitóide em laboratório este se mostrou trabalhoso e ineficiente. Os frutos contendo as lagartas expostas ao parasitismo foram colocados em gaiolas de madeira para que se pudesse aguardar a emergência de novos parasitóides, no entanto houve uma grande presença de fungos tornando-se necessária a abertura dos frutos e a retirada das lagartas. $O$ manuseio das lagartas na troca de meio de alimentação, ou seja, fruto para dieta artificial causou grande mortalidade de hospedeiro.

Tabela 2. Viabilidade pupal em porcentagem e número de macho e fềmeas de $H$. delicata em 3 gerações de laboratório

\begin{tabular}{cccccc}
\hline $\begin{array}{c}\text { Geração em } \\
\text { laboratório }\end{array}$ & $\begin{array}{c}\mathrm{N}^{\mathrm{o}} \text { de pupas de } \\
\text { H.delicata }\end{array}$ & $\begin{array}{c}\mathrm{N}^{\mathrm{o}} \text { de adultos de } \\
\text { H. delicata }\end{array}$ & $\begin{array}{c}\text { Viabilidade } \\
\text { pupal }\end{array}$ & $\begin{array}{c}\mathrm{N}^{0} \text { de } \\
\text { machos }\end{array}$ & $\begin{array}{c}\mathrm{N}^{0} \mathrm{de} \\
\text { fêmeas }\end{array}$ \\
\hline $1^{\mathrm{a}}$ & 79 & 68 & $86,08 \%$ & 49 & 19 \\
$2^{\mathrm{a}}$ & 22 & 17 & $77,27 \%$ & 7 & 10 \\
$3^{\mathrm{a}}$ & 20 & 14 & $70,00 \%$ & 5 & 9 \\
\hline
\end{tabular}

A fim de buscar melhorias no método de criação de $H$. delicata algumas tentativas de se expor as lagartas de $G$. aurantianum aos parasitóides sem a utilização de frutos foram realizadas instalando-se quatro testes. Nos três primeiros testes utilizou-se "frass" como atrativo às fêmeas de $H$. delicata, pois durante a manutenção dos parasitóides em três gerações de laboratório observou-se a atração das fêmeas pelo "frass". No $1^{\circ}$ teste confeccionaram-se mini-gaiolas formadas por um anel de acrílico de $20 \times 0,6 \mathrm{~mm}$ cuja base foi composta por tampa plástica 
de $20 \mathrm{~mm}$ de diâmetro e a parte superior fechada por tela de náilon. Cada minigaiola conteve de seis a oito lagartas de cada ínstar do bicho-furão, pedaços de dieta artificial como fonte de alimento e "frass" de lagartas criadas em laranja (possível fonte de atração do parasitóide). As mini-gaiolas foram coladas em um fruto de laranja Pêra e acondicionadas em gaiolas maiores (copo plástico transparente de $700 \mathrm{ml}$ (Fig. 3A). Em cada gaiola foi liberado um casal do parasitóide, sendo os adultos alimentados com mel puro, oferecido em gotas e água, esta mantida em rolo dental umedecido. Foram preparadas oito gaiolas e as lagartas ficaram expostas ao parasitismo de 24 a $48 \mathrm{~h}$. Após este período, as lagartas foram retiradas das mini-gaiolas e transferidas para tubos de vidro contendo dieta artificial para que pudessem completar seu desenvolvimento. Embora as fêmeas de $H$. delicata tenham sido atraídas pelo "frass" de lagartas criadas em laranja Pêra, nenhuma lagarta, de qualquer uma das idades, foi parasitada.

No segundo teste, foram utilizadas quatro placas de acrílico de $60 \times 20 \mathrm{~mm}$ contendo cada uma, lagartas de $G$. aurantianum em quatro ínstares diferentes, pedaços de dieta artificial e "frass" de lagartas criadas em laranja (Fig. 3B). Em cada placa foi liberada uma fêmea de $H$. delicata previamente acasalada sendo que as lagartas permaneceram, portanto, diretamente expostas ao parasitóide durante $24 \mathrm{~h}$. Quatro repetições para cada idade foram instaladas. Neste teste, observou-se que as fêmeas de $H$. delicata quando em contato direto com lagartas de $G$. aurantianum se afastaram do hospedeiro.
No terceiro teste, utilizaram-se quatro placas acrílicas idênticas às do segundo teste contendo dieta artificial, porém, as lagartas encontraram-se dentro da dieta. Em cada orifício de entrada das mesmas, foi acrescentado "frass" de lagartas criadas em laranja. As placas foram colocadas em gaiolas (copo plástico transparente de $700 \mathrm{ml}$ ) contendo um casal do parasitóide (Fig. 3C). Neste teste verificou-se que embora tenham sido atraídas pelo "frass", as fêmeas de $H$. delicata não realizaram qualquer tentativa de parasitismo. Durante este ensaio observou-se que os machos de $H$. delicata permaneceram mais tempo sobre a dieta artificial em relação às fêmeas.

No quarto teste, acrescentou-se à dieta artificial de $G$. aurantianum óleo cítrico nas concentrações mínima de 0,05 $\mathrm{ml}$ e máxima de 2,4 e $8 \mathrm{ml}$. Como estas concentrações não afetaram o desenvolvimento larval do bicho-furãodos-citros (Milano et al., 2006), foram preparadas as dietas artificiais, as quais foram colocadas em formas plásticas de forma arredondada utilizadas para a confecção de bombons (Fig. 3D). Este procedimento foi realizado com o objetivo de fazer com que a dieta artificial assumisse $o$ aspecto de um pequeno fruto. Lagartas de $1^{\circ}$ a $4^{\circ}$ ínstares foram colocadas nestas dietas e após 24 h, quando já haviam penetrado no meio artificial, foram expostas ao parasitismo por $H$. delicata durante $24 \mathrm{~h}$. O acréscimo de óleo cítrico na dieta artificial atraiu as fêmeas de $H$. delicata até a dieta, porém a fêmea não parasitou nenhum dos ínstares testados de seu hospedeiro. 

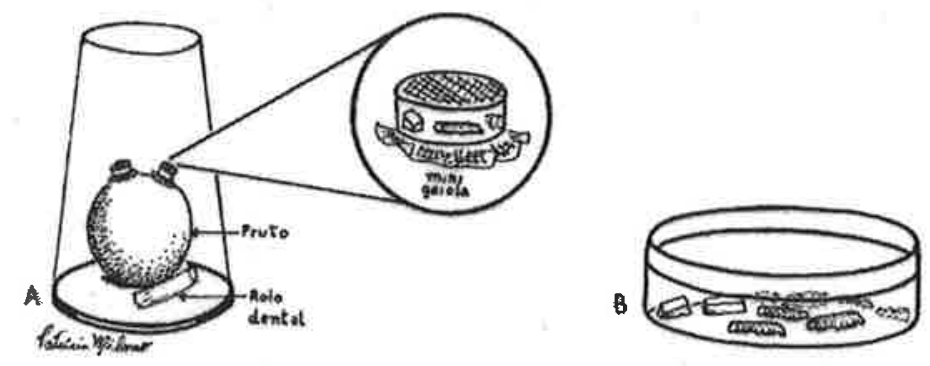

c
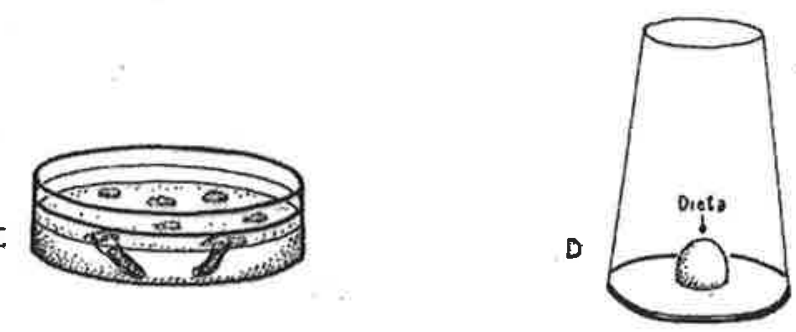

Figura 3. A- Mini-gaiolas coladas em um fruto de laranja Pêra e acondicionadas em gaiolas (copo plástico transparente de $700 \mathrm{ml}$ ); B- placas de acrílico de $60 \times 20 \mathrm{~mm}$ contendo pedaços de dieta artificial e "frass" de lagartas criadas em laranja e lagartas de G. aurantianum; Cplacas de acrílico de $60 \times 20 \mathrm{~mm}$ contendo lagartas em meio a dieta artificial e D- dieta artificial em forma arredondada contendo óleo cítrico.

Durante a manutenção das três gerações em laboratório de $H$. delicata pode-se observar que a atração dos parasitóides até seus hospedeiros depende de vários fatores e, pode ser estudada através do "comportamento de busca" destes insetos. $O$ sucesso na relação parasitóide-hospedeiro está relacionado a fatores como: hábitat, local de desenvolvimento, aceitação, conveniência e regulação do hospedeiro, assim como a capacidade do parasitóide vencer os sistemas de defesa do hospedeiro, a presença de toxinas ou a insuficiência nutricional, competição com outros parasitóides, seja intra ou inter específica (Vinson \& Iwantsch, 1980), componentes químicos presentes no "frass" de seus hospedeiros (Parra et al., 1996), componentes cuticulares, secreções, feromônio sexual liberados pelos adultos dos hospedeiros (Vinson, 1985) e ainda o tipo de danos causados em plantas hospedeiras (Van Poeke et al., 2003).
Ao se observar o comportamento das fềmeas de $H$. delicata nos frutos infestados por G. aurantianum verificou-se que as mesmas são atraídas pelo "frass" de seus hospedeiros. Ao encontrarem uma massa de "frass", as fềmeas vão inspecioná-la, tocando-a com as antenas (Fig. 4A) e em alguns casos, inclinando-se sobre a massa "tateando-a" com as mandíbulas. Em seguida, as fêmeas realizam a introdução do ovipositor na massa de "frass" até conseguirem atingir o orifício de entrada do hospedeiro, parasitando-o em seguida (Fig. 4C). Em algumas ocasiões, as fêmeas realizaram inspeções movimentos circulares ao redor do "frass" com o ovipositor na posição vertical apoiado pelas bainhas (Fig. 4B) para posteriormente realizarem a introdução do mesmo no orifício de entrada do hospedeiro. Este comportamento demonstra que outros estímulos podem estar sendo "percebidos" pelo ovipositor. Brow \& Anderson (1998) estudaram o 
ovipositor da vespa Trybliographa rapae (Hymenoptera: Figitidae) em microscópio de transmissão e observaram que havia sensilas na cutícula das válvulas ventrais. Estas sensilas são inervadas por seis dendritos os quais, possuem características termossensíveis. Neste estudo, os autores sugerem que o ovipositor tenha função gustativa e possa responder a estímulos recebidos da hemolinfa dos hospedeiros do parasitóide, além de responder a estímulos do substrato através de um segundo tipo de sensila mecanorreceptora. Em 2004, Guimarães \& Zucchi estudaram o comportamento de parasitismo de três espécies de parasitóides de moscas-das-frutas e observaram que em experimentos com olfatômetro de quatro vias, Aganaspis pelleranoi e Dicerataspis grenadensis foram mais atraídos pelos voláteis dos frutos infestados por larvas frugívoras; contudo, ao estudarem a seqüência comportamental dos eucoilíneos, em polpa de goiaba madura infestada com larvas de moscas, constataram que $A$. pelleranoi e Odontosema albinerve, ao chegarem nos frutos por meio dos voláteis, localizam as larvas hospedeiras nos frutos por meio de vibrotaxia e que $D$. grenadensis localiza as larvas hospedeiras nos frutos com o ovipositor.

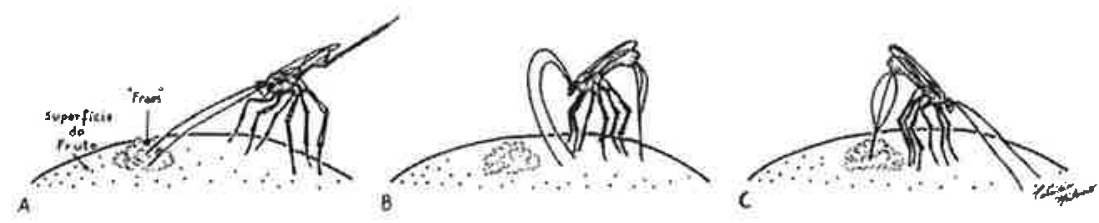

Figura 4. Fêmea de $H$. delicata em comportamento de busca à seu hospedeiro. A- Inspeção da massa de "frass" com as antenas; B- Tentativa de localização do hospedeiro através do ovipositor e C- Introdução do ovipositor na massa de "frass" (parasitismo do hospedeiro).

Diante destes resultados, e dos dados obtidos nesta pesquisa, provavelmente, estímulos químicos e físicos estejam associados ao comportamento de parasitismo de $H$. delicata, uma vez que nem todas as massas de "frass" atraíram o parasitóide. Estímulos físicos, como o fato do hospedeiro produzir pequenas vibrações ao se alimentar e o fato deste estar escondido no fruto, parecem ser fatores importantes para esta espécie, já que $H$. delicata não parasita hospedeiros expostos. A dieta artificial contendo ou não óleo cítrico, física e quimicamente diferente do fruto de laranja, explicaria o fato do parasitóide não realizar $o$ comportamento de inspeção verificado quando seu hospedeiro permaneceu nos frutos; ainda que o acréscimo de óleo cítrico no meio artificial tenha despertado o comportamento de inspeção de $H$. delicata, este não pôde localizar seu hospedeiro pela falta de estímulos físicos que, provavelmente, ficaram "camuflados".

Durante as três gerações de laboratório foi possível observar que $o$ período ovo-adulto para machos e fêmeas de $H$. delicata foi, em média, de 30,7 dias. A viabilidade pupal de $H$. delicata foi de $86 \% ; 77,27 \%$ e $70 \%$ para a $1^{\mathrm{a}}, 2^{\mathrm{a}}$ e $3^{\mathrm{a}}$ geração respectivamente (Tabela 2). As fêmeas viveram em média 14 dias. O acasalamento é rápido, durando de 10 a 15 segundos. O macho após se acasalar com 
uma primeira fêmea, não realiza um segundo acasalamento com outra fêmea, chegando até mesmo a "fugir" de novos acasalamentos.

Embora características do comportamento de $H$. delicata comecem a ser desvendadas, faltam muitos dados para se chegar a uma criação massal, visando sua liberação em campo. Ficou evidente que existe uma interação do fruto com o parasitismo, provavelmente ligado a fatores químicos e/ou físicos. O "frass" pode conter alguns componentes químicos que atraiam o parasitóide, mas não o suficiente para que ocorra o parasitismo. Portanto, devem ocorrer interações, ainda não esclarecidas no presente trabalho.

Os baixos parasitismos obtidos ao longo das gerações e cessação de parasitismo na $3^{\mathrm{a}}$ geração de laboratório mostraram que muitos aspectos comportamentais precisam ser estudados. Um aspecto a ser discutido é a grande variação com relação ao ínstar preferencial para parasitismo. Talvez o número ótimo de indivíduos por recipiente de criação possa ter afetado a ação do parasitóide (Peters \& Barbosa., 1977).

\section{AGRADECIMENTOS}

Ao técnico fitossanitário José David de Souza, da Fazenda Sete Lagoas, MogiGuaçu, SP, pelo auxílio nas coletas dos frutos, à $\operatorname{Prof}^{\mathrm{a}} \operatorname{Dr}^{\mathrm{a}}$ Angélica Maria Penteado-Dias (UFSCAR) pela identificação dos parasitóides e à Citrosuco-FISCHER S/A pelo suporte às pesquisas.

\section{REFERÊNCIAS BIBLIOGRÁFICAS}

ACHTERBERG, C. 1993. Revision of the subfamily Macrocentrinae Foerster (Hymenoptera: Braconidae) from the Palaeartic region. Zoologische Verhandelingen Leinden. 286: 1-110.
BROW, P. E. \& ANDERSON, M. 1998. Morphology and ultrastructure of sense organs on the ovipositor of Trybliographa rapae, a parasitoid of cabbage root fly. Journal Insect Physiology. 44: 1017-1025.

GARCIA, M. S. Bioecologia e potencial de controle biológico de Ecdytolopha aurantiana (LIMA, 1927) (Lepidoptera: Tortricidae), o bichofurão-dos-citros, através de Trichogramma pretiosum RILEY, 1879. Piracicaba, 1998. 118 p. Tese (Doutorado) - Escola Superior de Agricultura "Luiz de Queiroz", Universidade de São Paulo.

GARCIA, M. S. \& PARRA, J. R. P. 1999. Comparação de dietas artificiais, com fontes protéicas variáveis, para criação de Ecdytolopha aurantiana (LIMA) (Lepidoptera: Tortricidae). Anais da Sociedade Entomológica do Brasil. 28: 219-232.

GUIMARÃES, J. A \& Zucchi, R. A. 2004. Comportamento de parasitismo de três espécies de Eucoilinae (Hymenoptera: Cynipoidea: Figitidae) parasitóides de moscas-das-frutas (Diptera). Neotropical Entomology. 33: $217-$ 224.

MILANO, P., CARVALHO, S. S. de, BERTI FILHO, E. \& ODA, M. L. 2006. Influência do óleo cítrico e de corante artificial na biologia de Ecdytolopha aurantiana (Lepidoptera: Tortricidae) para estudos futuros sobre a atração e o desenvolvimento do seu parasitóide. Resumos/Biologia. $\mathbf{2 1}^{\circ}$ Congresso Brasileiro de Entomologia. Recife-PE.

PARRA, J. R. P., VINSON, S.B., GOMES, S. M. \& CÔNSOLI, F. L. 1996. Flight response of Habrobracon hebetor (Say) (Hymenoptera: Braconidae) in a wind tunnel to volatiles associated with infestations of Ephestia kueniella Zeller 
(Lepidoptera: Pyralidae). Biological Control. 6: 143-150.

PETERS, T. M. \& BARBOSA, P. 1977. Influence of population density of size, fecundity, and developmental rate of insects in culture. Annual Review of Entomology. 22: 431-434.

VAN POEKE, R. M. P., ROOSJEN, M., PUMARINO, L. \& DICKE, M. 2003. Attraction of the specialist parasitoid Cotesia rubecula to Arabidopsis thaliana infested by host or non-host herbivore species. Entomologia Experimentalis et Applicata. 107: 3 .

VINSON, S. B. \& IWANTSCH, G. F.. 1980. G.F. Host suitability for insect parasitoids. Annual Review of Entomology. 25: 397- 419.

VINSON, S. B. 1985. The behavior of parasitoids in KERKUT, G.A. \& GILBERT, L.I. Comprehensive insect physiology, biochemistry and pharmacology. 9: 417- 457.

WHARTON, R. A., MARSH, P. M. \& SHARKEY, M. J. 1997. Manual of the New World genera of the family Braconidae (Hymenoptera). Special Publication of the International Society of Hymenopterists. 1: 311315. 